\title{
CALIBRATION OF THE ON-LINE AEROSOL MONITOR (OLAM) WITH AMMONIUM CHLORIDE AND SODIUM CHLORIDE AEROSOLS
}

\author{
J. E. Brockmann, G. Pentecost", D. A. Lucero, and T. Romero
}

\begin{abstract}
The On-Line Aerosol Monitor (OLAM) is a light attenuation device designed and built at the Idaho National Engineering Laboratory (INEL) by EG\&G Idaho. Its purpose is to provide an on-line indication of aerosol concentration in the PHEBUSFP tests. It does this by measuring the attenuation of a light beam across a tube through which an aerosol is flowing. The OLAM does not inherently give an absolute response and must be calibrated. A calibration has been performed $a:$ Sandia National Laboratories' (SNL) Sandia Aerosol Research Laboratory (SARL) and the results are described here. Ammonium chloride and sodium chloride calibration aerosols are used for the calibration and the data for the sodium chloride aerosol is well described by a model presented in this report. Detectable instrument response is seen over a range of $0.1 \mathrm{~cm}^{3}$ of particulate material per $\mathrm{m}^{3}$ of gas to $10 \mathrm{~cm}^{3}$ of particulate material per $\mathrm{m}^{3}$ of gas.
\end{abstract}

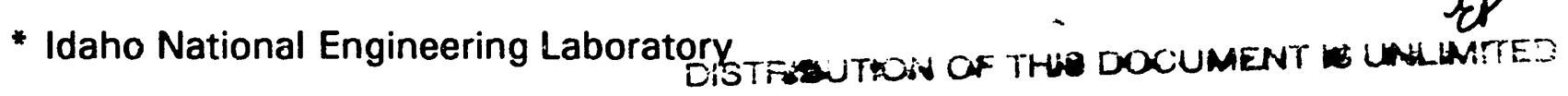




\section{Contents}

Section

Page

1.0 Introduction $\ldots \ldots \ldots \ldots \ldots \ldots \ldots \ldots \ldots \ldots \ldots \ldots \ldots \ldots$

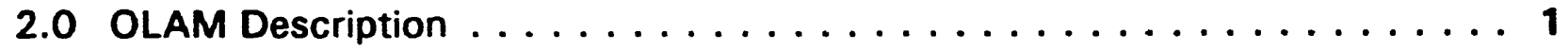

3.0 Aerosol Generation $\ldots \ldots \ldots \ldots \ldots \ldots \ldots \ldots \ldots \ldots \ldots \ldots \ldots \ldots \ldots \ldots \ldots$

3.1 Vapor Phase Reaction Aerosol Generator . . . . . . . . . . . . . . . 3

3.2 Atomization Aerosol Generator ................. 5

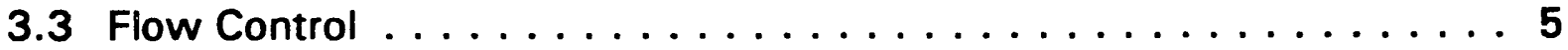

4.0 Experimental Test Setup . . . . . . . . . . . . . . . . 7

5.0 Quality Assurance ............................ 10

6.0 OLAM Calibration Points $\ldots \ldots \ldots \ldots \ldots$

6.1 Ammonium Chloride Aerosol . . . . . . . . . . . . . . . . 10

6.2 Sodium Chloride Aerosol . . . . . . . . . . . . . . . . . 11

6.3 Calibration Data Sets ... . . . . . . . . . . . . . . . 14

6.4 OLAM Response and Observations . . . . . . . . . . . . . . 14

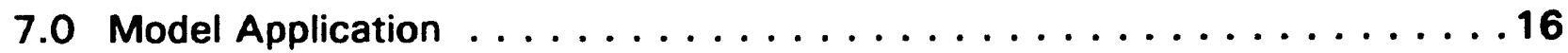

8.0 Summary and Conclusions $\ldots \ldots \ldots \ldots \ldots$

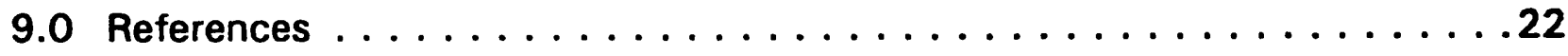

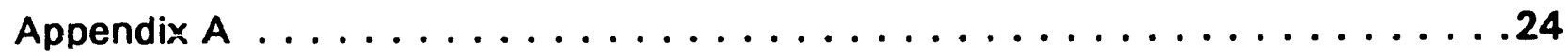

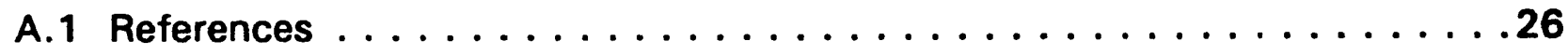




\section{Figures}

Figure

Page

1. Schematic diagram of the vapor phase reaction aerosol generator used in the OLAM calibration ..................... 4

2. Schematic diagram of the atomization aerosol generator used in the OLAM calibration . . . . . . . . . . . . . . . . . . . . 6

3. Schematic diagram of the experimental test setup used in the OLAM calibration

4. Photographs of the aerosol generator setup with the OLAM and aerosol sampling filter and impactor .................... 9

5. Electron micrographs of $\mathrm{NH}_{4} \mathrm{Cl}$ particles collected on impactor stages . . . 12

6. Photograph of airfoils inside OLAM showing deposition of $\mathrm{NH}_{4} \mathrm{Cl}$ particles .13

7. OLAM calibration data for $\mathrm{NH}_{4} \mathrm{Cl}$ and $\mathrm{NaCl}$ particles shown as percent attenuation as a function of aerosol volume concentration $\ldots \ldots \ldots$

8. OLAM calibration data for $\mathrm{NH}_{4} \mathrm{Cl}$ and $\mathrm{NaCl}$ particles shown as percent attenuation as a function of aerosol volume concentration for the $1 \mathrm{~cm}$

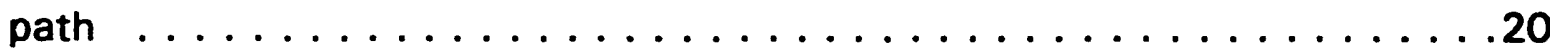

9. OLAM calibration data for $\mathrm{NH}_{4} \mathrm{Cl}$ and $\mathrm{NaCl}$ particles shown as percent attenuation as a function of aerosol volume concentration for the $3 \mathrm{~cm}$

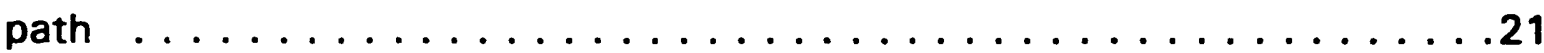

A-1. Volume normalized extinction coefficient for lognormal distributions . . . . 27

A-2. Volume normalized extinction soefficients for lognormal distributions shown as a function of mean diameter for various geometric standard deviations and as a function of geometric standard deviation for various mean diameters 


\section{Tables}

Tabile

1. Aerosol calibration data giving geometric mass mean aerodynamic diameter, geometric standard deviation, aerosul mass concentration, and aerosol volume concentration tabulated with the corresponding OLAM response for the $1 \mathrm{~cm}$ and $3 \mathrm{~cm}$ path lengths $\ldots \ldots \ldots \ldots \ldots \ldots \ldots$

2. Comparison of the measured values of attenuation to the values calculated from the model for calibration points 10,11 , and 12 with sodium chloride aerosol. The geometric mass mean volume equivalent diameter is calculated from the geometric mass mean aerodynamic equivalent diameter using a material density for sodium chloride of $2.165 \mathrm{~g} / \mathrm{cm}^{3}$ and assuming spherical particles at the test conditions of $8.3 \times 10^{5} \mathrm{dynes} / \mathrm{cm}^{2}$ and $21 \mathrm{C}$. The refractive index of sodium chloride used in the calculation is 1.544. The geometric mass mean volume equivalent diameter, the geometric standard deviation, and the aerosol volume concentrations for each point are given with the measured and calculated attenuation for the $1 \mathrm{~cm}$ and $3 \mathrm{~cm}$ path

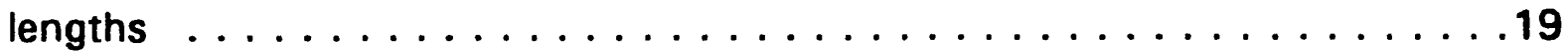




\subsection{INTRODUCTION}

This document provides the results of the calibration of the On-Line Aerosol Monitor (OLAM) performed at Sandia National Laboratories (SNL) in May 1992. G. Pentecost from Idaho National Engineering Laboratory (INEL) set up and operated the OLAM and took the OLAM data. J. Brockmann, D. Lucero, and T. Romero from SNL set up and operated the aerosol generation equipment and measured the aerosol passing through the OLAM.

The OLAM is an instrument designed to measure the attenuation of a light beam across a tube through which an aerosol is flowing. It gives a response proportional to the aerosol concentration flowing through the light beam. The most effective way to use this instrument is in conjunction with discrete physical aerosol samples taken with filters or impactors so that the OLAM signal can be correlated with the measured aerosol concentration and used to interpolate the continuous aerosol concentration at times between the discrete physical aerosol samples. The OLAM also provides an indication of events characterized by changes in the aerosol concentration and as such is useful in providing a cue to take a discrete physical aerosol sample.

The OLAM is not a device that inherently gives an absolute response and as such it must be calibrated with the aerosol it is intended to measure. However, calibration with another atrosol does provide a good qualitative response that will allow the user to assess the efficacy of the device. It is this purpose that this calibration is designed to serve.

\subsection{OLAM DESCRIPTION}

The On-line Aerosol Monitor (OLAMI) is described by Adams et al. (1986). The instrument consists of three primary elements: the remote-control computer, the optics and detection/amplification electronics, and the spool piece through which the aerosols flow. The spool piece consists of a $3 \mathrm{~cm}$ diameter flow path for aerosols across which two LED light beams at 0.841 micrometers wavelength shine. One shines through ports or windows in the spool piece wall and has a path of $3 \mathrm{~cm}$. The other shine through ports across the ends of airfoils extending normal to the spool piece wall to within $1 \mathrm{~cm}$ of each other and has a path of 1 $\mathrm{cm}$. The $3 \mathrm{~cm}$ path will yield more attenuation than the $1 \mathrm{~cm}$ path and will be more sensitive to lower concentrations. At higher concentrations, the $1 \mathrm{~cm}$ path will continue to give resolvable signals after the $3 \mathrm{~cm}$ path fully obscures the beam. The dynamic range of the instrument is increased by the use of two paths of differing lengths.

The instrument response can be described by the Lambert-Beer law for attenuation of a light beam. 


$$
\frac{1}{T_{0}}=\exp \left(-\beta_{\text {ext }} L\right)
$$

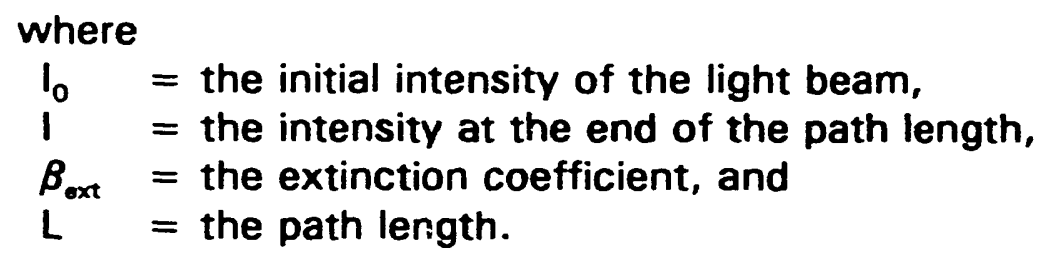

The percent attenuation is

$$
A \text { tn }=100\left[1-\exp \left(\beta_{\text {oxt }} L\right)\right]
$$

The extinction coefficient is the sum of the extinction cross sections of all the particles per unit volume in the aerosol distribution that are extinguishing the light. Brockmann (1976) and Willeke and Brockmann (1977) have shown the development of a volume normalized extinction coefficient for lognormal particle volume distributions. In this treatment, the extinction coefficient normalized with respect to the aerosol volume concentration (the mass concentration divided by the aerosol material density) is given as a function of the log-normal distribution parameters geometric mass (or volume) mean particle diameter and geometric standard deviation. The performance of the OLAM can then be described by the attenuation of the signal as a function of the aerosol mass (or volume) concentration for a given size particle distribution. This response to aerosol mass concentration is beneficial because the mass concentration is the primary aerosol quantity of interest. The release and transport of material are best described as mass and the quantities measured by filter samples and impactor samples are aerosol mass concentration and distribution. One of the principal uses of the OLAM is to interpolate between physical mass concentration measurements.

After arriving from another site, the equipment was unpacked, reconnected, and checked for damage. No shifping damage occurred. All of the components were checked for dependability, consistency, and operational characteristics during the calibration process. First, equipment stability was examined during continual, extended operation without aerosols. Then, system response was observed while aerosols were generated through the flow path.

The system was then checked for extended stability and error-free function. The equipment was monitored for signal drift and dependable remote-control operation by an IBM-AT computer during 95 hours of continual operation at ambient temperature without aerosols. The greatest electro-optic signal drift relative to the initial levels was $-8.87 \%$, at a maximum change of $-1.1 \%$ per hour. The remotecontrol functioned without any problems. The computer program operated as designed; constantly monitoring optical signal outputs and allowing equipment settings to be controlled from the computer keyboard. 


\subsection{AEROSOL GENERATION}

Calibration aerosols were generated in two ways. The first method produces ammonium chloride particles from a gas phase chemical reaction between ammonia and hydrogen chloride. The reaction produces a low vapor pressure material, ammonium chloride, that nucleates and condenses into high concentration ultrafine particles that grow by coagulation. The gas phase acid-base reaction has been used by Adams et al. (1986) to generate ammonium chloride aerosols and by Brockmann et al. (1982) to generate ammonium sulfate aerosols. The second method produces sodium chloride particles by spray drying of an atomized solution of sodium chloride in water. This method produces larger particles at lower number concentration.

\subsection{Vapor Phase Reaction Aerosol Generator}

The ammonium chloride aerosol generator is a vapor phase reaction aerosol generator and is shown schematically in Figure 1 . It consists of a mixing section in which the reactant gases and a carrier gas of dry air are mixed, a growth section in which the gases react to form nuclei which grow by condensation and subsequent coagulation, a flow diluter which can be used to add additional dry air, and a transport section which consists of two bypass diluters in series. Of course, coagulation continues through the dilution sections, especially if little or no dilution is performed. This generator produces aerosol particles with a number concentration as high as $10^{8}$ to $10^{9}$ particles par $\mathrm{cm}^{3}$ of gas. The number concentration is determined by the rate of particle coagulation. Initially high concentrations of nuclei that grow by condensation will coagulate at a rate proportional to the square of their concentration and will thus rapidly approach a number concentration dependent on the overall coagulation time and independent of the aerosol mass. In this type of aerosol generation system, the number concentration is determined by coagulation time and the particle size is determined by the aerosol mass available to be distributed among the particles. The diluters allow the concentration of a given aerosol distribution to be reduced without appreciably affecting the size of the particles. There will be some variation of residence time for different flows and dilutions resulting in some slight variation in particle size.

The reactant gases, ammonia and hydrogen chloride, are delivered to the generator through flow controlling orifices at a rate on the order of 1 to $5 \mathrm{~cm}^{3}$ per second. Dry air is delivered along with the reactant gases to the first mixer. The total air flow of 15 to 25 liters per minute is split evenly among the two reactant gas streams to provide transport air and a clean air stream. These gas streams enter the mixer as three coaxial streams with the hydrogen chloride and dry air mixture in the center, the clean air stream next and the ammonia and dry air mixture outside of that. This configuration uses the center coaxial flow to keep the reaction from taking place at the tube exits, which avoids plugging the mixer outlet. 


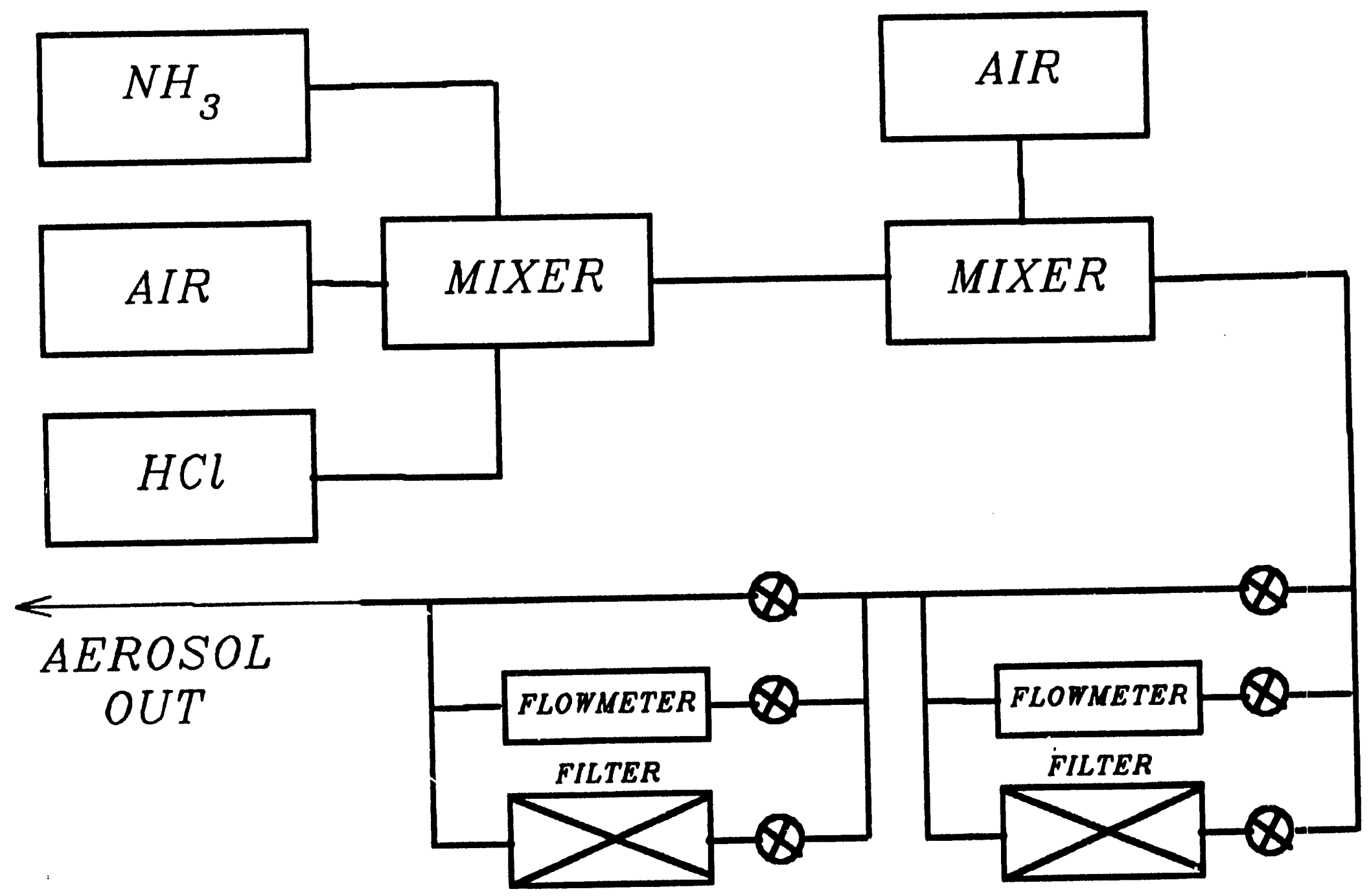

Figure 1. Schematic diagram of the vapor phase reaction aerosol generator used in the OLAM callbration. 
The growth section consists of $102 \mathrm{~cm}$ of $2.2 \mathrm{~cm}$ diameter aluminum tubing comprising a volume of $490 \mathrm{~cm}^{3}$. Resident times in the first growth section are between 1 and 1.6 seconds.

The second mixer at which the first dilution takes place consists of a porous sintered metal tube contained in a cylindrical housing. The aerosol flows through the tube while dilution air introduced into the annular volume of the housing flows through the porous walls of the tube where it mixes with and dil: ites the aerosol. The dilution flow used is up to 70 liters per minute.

The transport section consists of two bypass diluters in series. The bypass diluters operate on the principle of dividing the aerosol flow into two paths, passing one path through a filter, removing the particles, and the other path through a flow measuring device. The flows are recombined resulting in a dilution of the original aerosol. In this system, the flow can bypass either of the diluters completely, resulting in no dilution. When in use, the valves to the flowmeter and filter are opened and the valve bypassing the diluter is closed. The flowmeter is an orifice plate designed to minimize inertial losses for particles of 10 micrometers and less. The flow path through the flowmeter can handle up to 25 liters per minute of flow at a pressure drop of approximately 10 inches of water. The pressure drop is monitored with Magnehelic differential pressure gauges. The flow through the flowmeter, and hence the dilution ratio, is controlled by feathering the valve to the filter.

\subsection{Atomization Aerosol Generator}

The sodium chloride aerosol generation system is an atomization aerosol generator. It is shown schematically in Figure 2. It consists of a Collison type atomizer used to atomize a $216 \mathrm{gm} / \mathrm{liter}$ (1:10 by volume) solution of sodium chloride in water into a drying volume containing a desiccant. The particle size is determined primarily by the solution concentration although the atomizer flow rate has some effect. The aerosol concentration is varied by using various combinations of atomizer flow and dilution air. The atomizer flow has been calibrated with an upstream pressure transducer in place using the gas clock to give a direct correlation between flow and transducer output. The dilution flow is supplied by the same orifice transducer combination used in the ammonium chloride aerosol generator.

\subsection{Flow Control}

Flows are controlled using calibrated critical orifices with regulation of upstream pressure that is measured with calibrated pressure transducers. The air flows in the system have been calibrated with orifices and transducers in place using a gas clock that has been calibrated in the SNL primary standards laboratory; The flow calibration is NIST traceable. the atomizer has also been calibrated with an 
○)

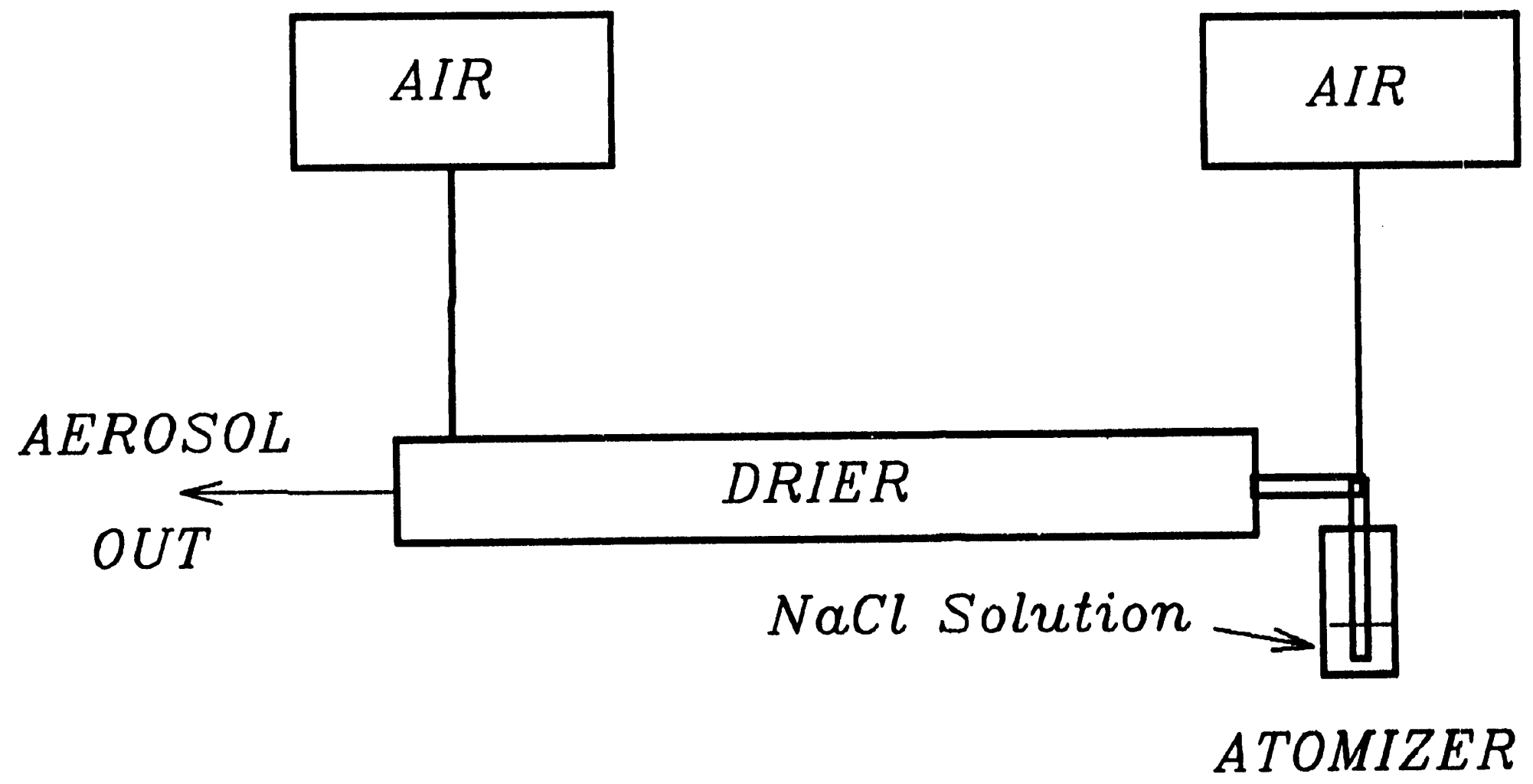

Figure 2. Schematic diagram of the atomization aerosol generator used in the OLAM callbration. 
upstream pressure transducer in place. This gives a direct correlation of flow to transducer output for the system as it is operated and reduces the potential for error. The flows of the reactant gases are controlled using critical orifices. The actual reactant gases could not be used for the flow calibration. This difficulty was overcome by calibrating with air and adjusting the calibration based on molecular weights of the gases. These orifices were calibrated using a bubble flow meter that has been calibrated in the SNL primary standards laboratory. Again, the calibrations have been performed with the upstream pressure transducers in place so that a direct correlation of flow to transducer output is obtained.

\subsection{EXPERIMENTAL TEST SETUP}

A schematic of the experimental test set up is shcwn in Figure 3. The aerosol from the aerosol generator, either ammonium chloride or sodium chloride, flows into the OLAM. The aerosol generators are set up in a fume hood. The OLAM and the filter and impactor aerosol samplers are external to the hood. The exhaust gas from the OLAM and samplers is returned to the hood and filtered before venting in the hood.

Purge gas to the beam ports, or windows, is regulated by two rotameters, one for each set of windows. The flow from each rotameter is split, half going to each window in a set. The flow is set to produce a gas velocity through the window of approximately $10 \%$ of the gas velocity through the OLAM. The OLAM control system is set up next to the OLAM and the output for the light attenuation is recorded on a strip chart with periodic readings also written onto the chart.

The outputs of the aerosol generators going through the OLAM were directly measured by filter and impactor for each data point. This avoids uncertainty in generator performance because the measurements will indicate if the generator is not operating properly. The filter sample is drawn at a flow rate of 8.4 liters per minute through a 47 millimeter diameter Millipore type HA membrane filter with a 0.45 micrometer pore size. The impactor sample is drawn through an Andersen Mark III cascade impactor at a flow of 14.75 liters per minute. The collection substrates are the glass fiber substrates provided by the manufacturer. The flows are controlled with critical orifices that have been calibrated by the SNL primary standards laboratory. The flows through an assembled impactor and filter were checked with a calibrated bubble flow meter and found to be within calibration. The impactor has been calibrated at the Sandia Aerosol Research Laboratory (Rader et al., 1991) and this calibration is used in reducing the data. The filters and collection substrates are weighed on balance with a NIST traceable calibration.

Figure 4 is a photograph of the vapor phase reaction aerosol generator set up with the OLAM and the aerosol sampling filter and impactor. 
$\infty$

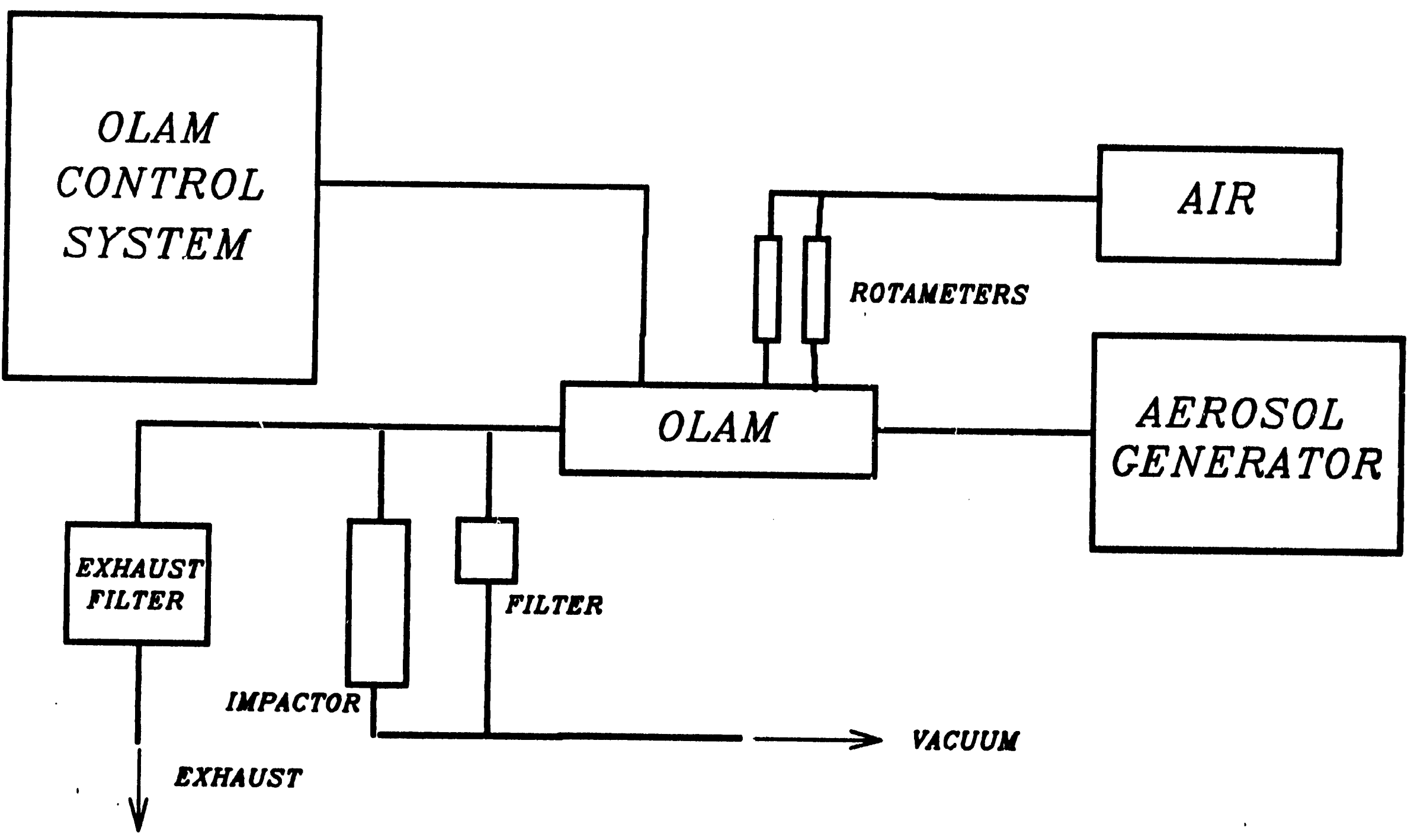

Figure 3. Schematic diagram of the experimental teat sotup used in the OLAM callbradion. 


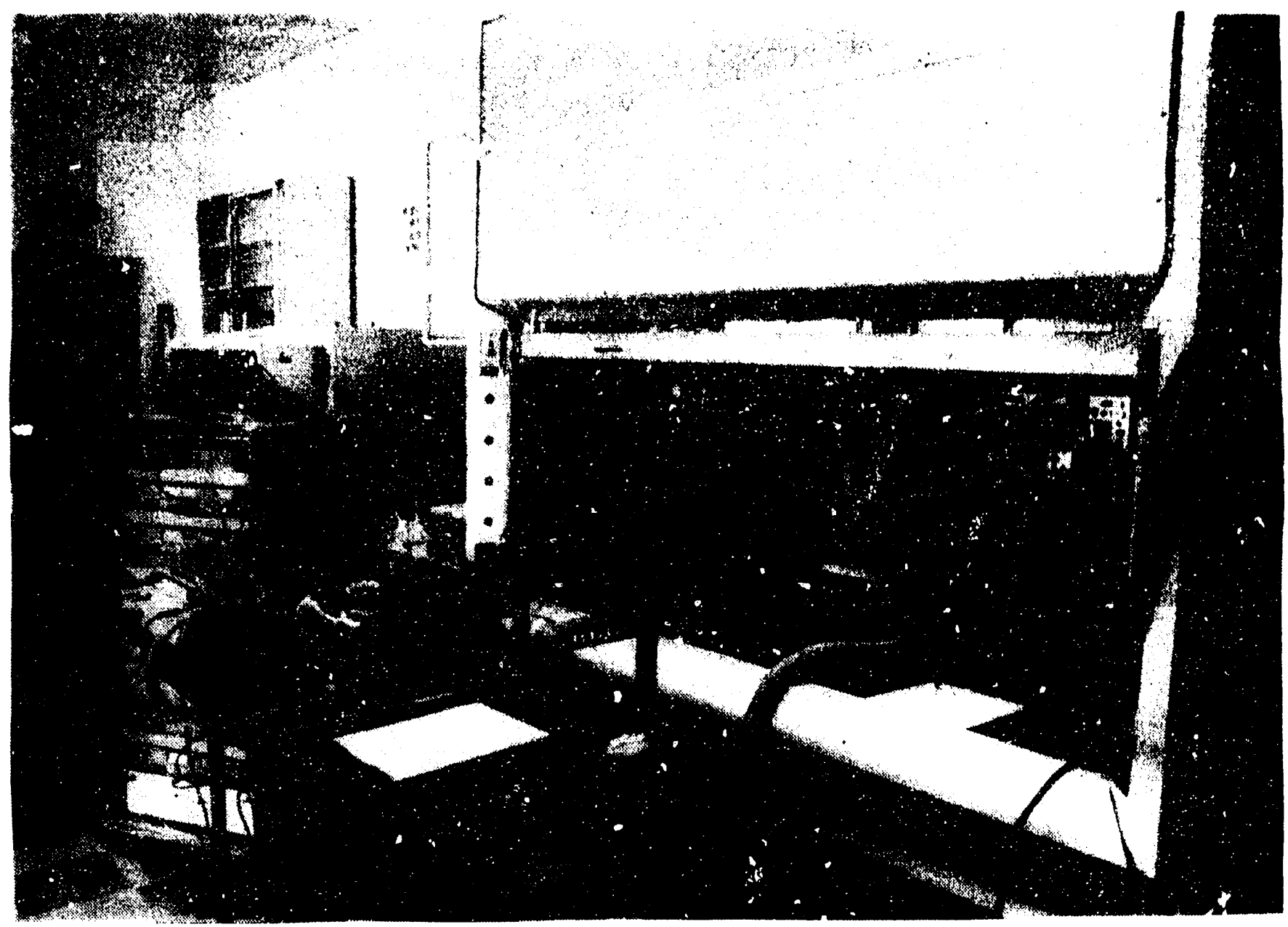

Figure 4. Photograph of the aerosol generator setup with the OLAM and aerosol sampling filter and impactor. 


\subsection{QUALITY ASSURANCE}

The assurance of quality in the data and calibration is addressed by the following measures:

1. The aerosol generation systems are designed to deliver calibration aerosols to the 'LAM at the sizes and in the concentration range desired.

2. Natio. Il Institute of Standards and Technology (NIST) traceable calibration standards are used to calibrate instiuments used for flow, mass, and pressure measurements.

3. Calibration of system flows is performed with the system assembled and the transducer and flow elements in place.

4. Sampler flow rates are controlled by critical orifices and calibration of sampler flows is performed with samplers fully assembled and in place.

5. The impactor has been calibrated in our laboratory and this response is used to analyze the particle size distribution.

6. The calibration aerosol is directly measured for each data point at the point of OLAM response which minimizes the number of additional measurements. The aerosol measurement is supported by the flow measurements aliowing estimates of generator performance to be made. The OLAM itself provides information on the invariance of the calibration aerosol over the measurement period.

\subsection{OLAM CALIBRATION POINTS}

Two particle size wirdows were identified over which calibration data were desired. The first was for particles nominally 0.1 micrometer in diameter (the Small Particle Window) at concentrations of $10^{7}$ to $10^{9}$ particles per $\mathrm{cm}^{3}$ of gas. This translates to about 0.005 to $0.5 \mathrm{~cm}^{3}$ of aerosol material per $\mathrm{m}^{3}$ of gas. The second was foi particles nominally 1 micrometer in diameter (the Large Particle Window) at concentrations of $10^{5}$ to $10^{7}$ particles per $\mathrm{cm}^{3}$ of gas which corresponds to about 0.05 to $5 \mathrm{~cm}^{3}$ of aerosol material per $\mathrm{m}^{3}$ of gas. The calibrations address these volume concentrations very well. The aerosol mass concentration is easily determined by multiplying the volume concentration by the material density of the aerosol particle material.

\subsection{Ammonium Chloride Aerosol}

The vapor phase aerosol generator produces ammonium chloride aerosol at high number concentrations (on the order of $10^{8}$ to $10^{9}$ particles per $\mathrm{cm}^{3}$ of gas). The material density of ammonium chloride is $1.527 \mathrm{~g} / \mathrm{cm}^{3}$. The generator has been operated at two concentration levels, $0.73 \mathrm{~g} / \mathrm{m}^{3}$, or $0.48 \mathrm{~cm}^{3}$ aerosol per $\mathrm{m}^{3}$ of gas and $6.9 \mathrm{~g} / \mathrm{m}^{3}$, or $4.5 \mathrm{~cm}^{3}$ aerosol per $\mathrm{m}^{3}$ of gas. The aerosol is diluted at various levels to provide a range of aerosol concentration covering a factor of about 50 on 
concentration. Electron micrographs of typical ammonium chloride particles collected on impactor substrates are shown in Figure 5.

Examination suggests that this ammonium chloride aerosol may have a considerable void fraction. This is not unusual in aerosols formed by agglomeration processes and is likely to be the case for some of the aerosols that the OLAM is intended to measure. A high void fraction would enhance particle loss by interception. This may have caused the enhanced deposition observed on some of the impactor plates. It can be argued that this could give an indicated mean size and spread of the distribution larger than actually present.

The expected ammonium chloride aerosol concentration based on the input reactant masses, flow rates, and dilution has been calculated assuming no losses. Comparison of this ideal aerosol concentration to the measured concentration indicates that some loss of aerosol material is occurring. The measured concentrations are typically $60 \%$ to $90 \%$ of the ideal concentrations. Examination of the generator has shown deposition of aerosol material on the tube walls after the first mixer indicating some type of flow deposition or reaction at or near the surface of the tube. Deposition farther downstream is in the form of sparse agglomerates suggesting interception as a deposition mechanism. The orifices in the bypass diluter flow meters have shown deposits arising from interception. On two occasions the orifices actually plugged.

It is important to recognize that these losses of aerosol in the generator and the occasional degraded performance of the generator by no means compromise the data. The data are taken at the point of measurement by the OLAM, which measures whatever actually arrives in the viewing regions. The attenuation measurement from the OLAM is correlated with the aerosol volume concentration determined from the filter measurement. Changes in generator performance such as declining concentration are flagged by the comparison of measured to ideal concertration given by the OLAM signal itself.

The airfoils through which the $1 \mathrm{~cm}$ path extends in the OLAM have been observed to have deposits of aerosol on their leading edges. Figure 6 is a photograph of the airfoils through the OLAM inlet. Some deposited material can be seen on the leading edges. Deposition on these leading edges is, again, thought to be due to interception of the non-spherical particles.

\subsection{Sodium Chloride Aerosol}

The atomization aerosol generator produces sodium chloride aerosols. The material density of sodium chloride is $2.165 \mathrm{~g} / \mathrm{cm}^{3}$. This aerosol is at a maximum concentration of $0.576 \mathrm{~g} / \mathrm{m}^{3}$, or $0.27 \mathrm{~cm}^{3}$ aerosol per $\mathrm{m}^{3}$ of gas, at a lower number concentration (on the order of $10^{6}$ to $10^{7}$ particles per $\mathrm{cm}^{3}$ of gas). This aerosol was diluted over a factor of about 7 . 

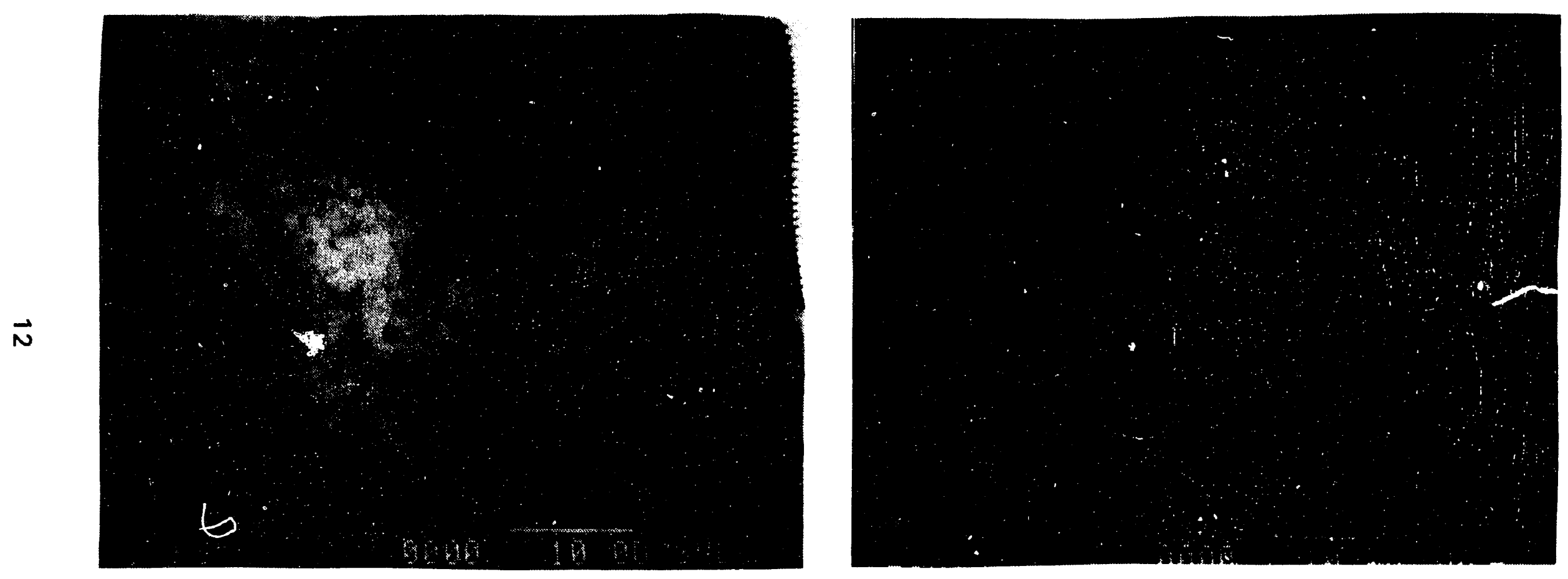

Figure 5. Electron micrographs of $\mathrm{NH}_{4} \mathrm{Cl}$ particles collected on impactor stages. 


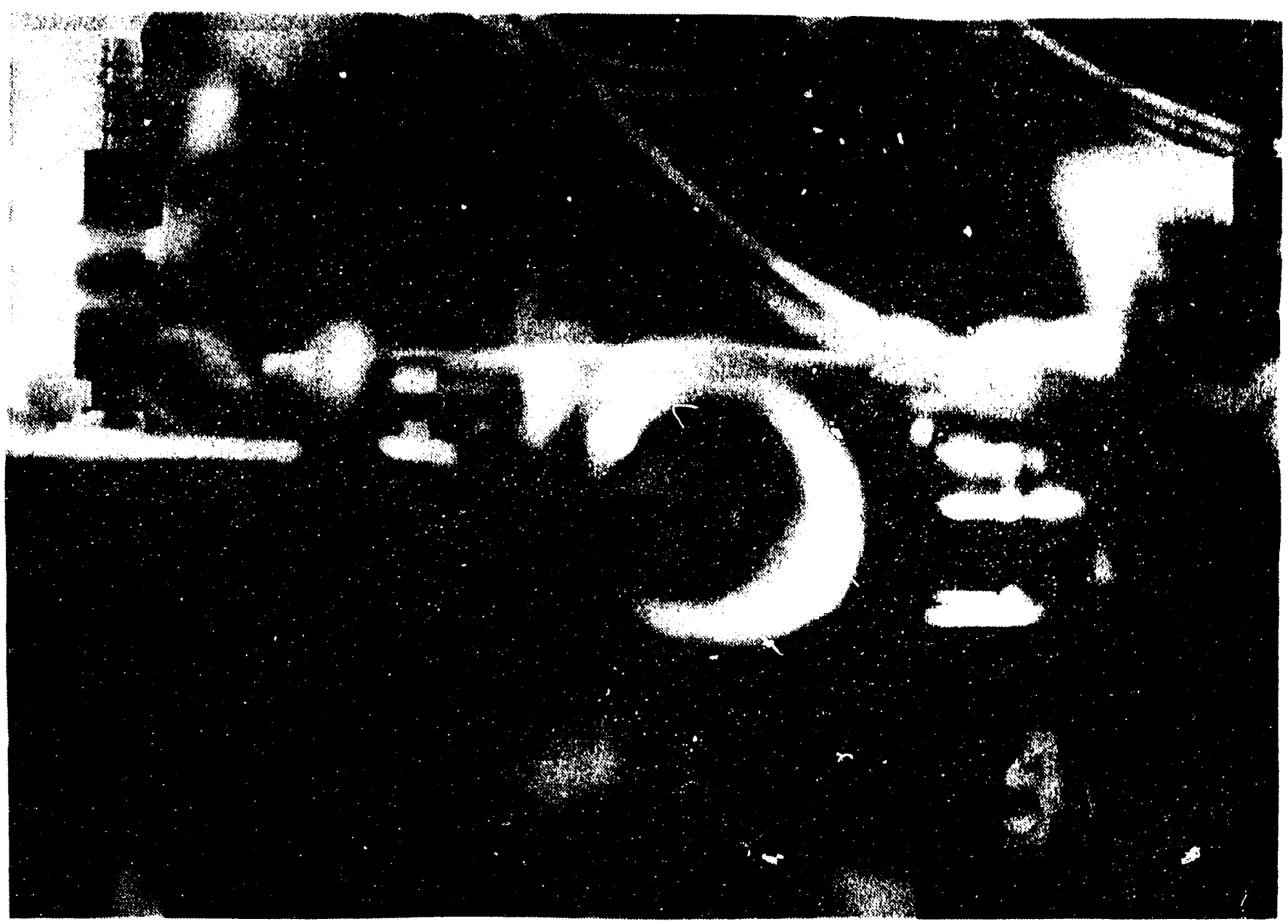

Figure 6. Photograph of airfoils inside OLAM showing deposition of $\mathrm{NH}_{4} \mathrm{Cl}$ particles. 
The sodium chloride aerosols are produced by spray drying and are assumed to be compact spherical particles. The impactor data for these particles are excellent and these data are used for the comparison of data to theory in a later section.

\subsection{Calibration Data Sets}

In Table 1, the calibration points are divided into four groups. Each group is taken with a given mass input and concentration is varied by dilution. It is assumed that the aerosol size is unafiected by the dilution and that the size of the particles is constant for a given set. This assumption is supported by the data.

The first group of calibration points (CAL 1-4) were obtained using ammonium chloride particles with high number concentrations and small sizes to address the Small Particle Window. The second group (CAL 5-9) is ammonium chloride particles and is for an aerosol with a relatively high rumber concentrations but larger sizes to address the Large Particle Window. CAL 6 was omitted because the OLAM indicated changing concentration during the measurement and CAL 9 is omitted because the measured concentration was too far below the ideal concentration. The third group of data (CAL 14,15,17) is ammonium chloride particles and is a repeat of the CAL 1 data point but with humidity added to the generator in an attempt to produce smaller more compact particles. These data address the Small Particle Window with high concentration and possibly smaller particle size than the first group. The fourth group (CAL 10-12) is sodium chloride particles from an atomizer and is for larger particles at lower number concentrations. This group addresses the Large Particle Window.

The measured aerosol results given in Table 1 are for each of the calibration runs mentioned above. The values of the measured aerosol mass and volume concentration, the measured geometric mass mean aerodynamic diameter, and the measured geometric standard deviation are given .vith the measured attenuation for the $1 \mathrm{~cm}$ and $3 \mathrm{~cm}$ light paths. The attenuation given is the average attenuation measured by the OLAM over the aerosol sampling period. The data points CAL 6 and CAL 9 indicate decreasing aerosol concentration over the sampling period and measured concentrations much lower than the ideal concentrations. They are not included in the analysis.

\subsection{OLAM Response and Observations}

The OLAM electronics and optics proved to be dependable during the calibration runs. The equipment continued to operate steadily without any problems, and the comparative reference signals remained stable. The detector/amplifiers provided more than enough signal to yield useful measurements. Even the lowest signal detected during the tests fell well within the mid-range output of the equipment. System noise was kept to a minimum; an open optical path produced noise equaling only $1.5 \%$ of the weakest test signal. 
Table 1

Aerosol calibration data giving geometric mass mean aerodynamic diameter, geometric standard deviation, aerosol mass concentration, and aerosol volume concentration tabulated with the corresponding OLAM response for the $1 \mathrm{~cm}$ and $3 \mathrm{~cm}$ path lengths.

\begin{tabular}{|c|c|c|c|c|c|c|}
\hline $\begin{array}{c}\text { Calibration } \\
\text { Point }\end{array}$ & $\mathrm{DGM}_{\infty}$ & $s_{0}$ & $\begin{array}{l}\text { Aerosol } \\
\text { Mass }\end{array}$ & $\begin{array}{l}\text { Aerosol } \\
\text { Volume }\end{array}$ & $\begin{array}{l}\text { Attenuation } \\
1 \mathrm{~cm} \text { path }\end{array}$ & $\begin{array}{l}\text { Attenuarion } \\
3 \mathrm{~cm} \text { path }\end{array}$ \\
\hline & micron & - & $\mathrm{g} / \mathrm{m}^{3}$ & $\mathrm{~cm}^{3} / \mathrm{m}^{3}$ & $\%$ & $\%$ \\
\hline CAL 1: $\mathrm{NH}_{4} \mathrm{Cl}$ & 0.45 & 2.3 & 0.73 & 0.48 & 1.23 & 2.78 \\
\hline $\mathrm{CAL} 2: \mathrm{NH}_{4} \mathrm{Cl}$ & 0.44 & 2.3 & 0.215 & 0.141 & 0.27 & 1.00 \\
\hline $\mathrm{CAL}$ 3: $\mathrm{NH}_{4} \mathrm{Cl}$ & 0.52 & 2.1 & 0.053 & 0.035 & 0.116 & 0.209 \\
\hline CAL 4: $\mathrm{NH}_{4} \mathrm{Cl}$ & 0.49 & - & 0.0185 & 0.0121 & 0.027 & 0.110 \\
\hline $\mathrm{CAL}$ 5: $\mathrm{NH}_{4} \mathrm{Cl}$ & 0.88 & 2.2 & 6.9 & 4.5 & 14.27 & 43.7 \\
\hline CAL 6: $\mathrm{NH}_{4} \mathrm{Cl}$ & 0.72 & 2.5 & 1.0 & 0.65 & 1.51 & 2.4 \\
\hline $\mathrm{CAL}$ 7: $\mathrm{NH}_{4} \mathrm{Cl}$ & 0.81 & 2.2 & 2.35 & 1.54 & 4.87 & 13.79 \\
\hline $\mathrm{CAL}$ 8: $\mathrm{NH}_{4} \mathrm{Cl}$ & 0.94 & 2.1 & 0.78 & 0.51 & 1.649 & 5.43 \\
\hline CAL 9: $\mathrm{NH}_{4} \mathrm{Cl}$ & 0.78 & 2.4 & 0.0096 & 0.0063 & 0.025 & 0.038 \\
\hline $\mathrm{CAL} \mathrm{14:} \mathrm{NH}_{4} \mathrm{Cl}$ & 0.52 & 1.7 & 0.66 & 0.43 & 0.338 & 1.052 \\
\hline CAL 15: $\mathrm{NH}_{4} \mathrm{Cl}$ & 0.40 & 1.6 & 0.59 & 0.39 & 0.312 & 1.015 \\
\hline CAL 17: $\mathrm{NH}_{4} \mathrm{Cl}$ & 0.46 & 2.1 & 0.54 & 0.35 & 0.406 & 1.584 \\
\hline CAL 10: $\mathrm{NaCl}$ & 1.06 & 2.0 & 0.576 & 0.266 & 1.175 & 3.63 \\
\hline CAL 11: $\mathrm{NaCl}$ & 0.95 & 2.6 & 0.31 & 0.143 & 0.634 & 1.692 \\
\hline CAL 12: $\mathrm{NaCl}$ & 1.36 & 2.3 & 0.088 & 0.041 & 0.169 & 0.459 \\
\hline
\end{tabular}


The spool piece produced distinct signal responses during aerosol flows. This was demonstrated when the $1-\mathrm{cm}$. and 3-cm. optical signals tracked the aerosols congruently. As expected, the 3-cm. path consistently displayed greater sensitivity than the $1-\mathrm{cm}$. path. During the heaviest aerosol flow (Calibration \#5), the $3-\mathrm{cm}$. signal decreased by $41 \%$, and the $1-\mathrm{cm}$. signal by $14 \%$. The instrument responded to both gradual and sudden shifts in concentration levels. In Calibration \#6, the steady decline in aerosol concentration was clearly visible. During other runs, the signal reacted sharply to the presence of aerosols, both at their initiation and removal.

The purge gas flows for the windows were very important in preventing a decline in the average signal level during aerosol flows. During instances of low purge flow, the optical signal did decrease steadily even though the aerosols were kept uniform. During the higher concentrations of Calibration \#5, the post-aerosol optical signal did not return to the full pre-aerosol level. The $16 \%$ decline in baseline signal level indicated a degree of aerosol deposition inside the spool piece, either directly on the diamond window or around the light-path orifices. Increasing the purge flow temporarily afterwards appeared to improve optical transmission.

The attenuation results are given in Figure 7 in which the percent attenuation as indicated by the OLAM is plotted as a function of the aerosol volume concentration as measured by the filters. These data cover the range of aerosol volume concentration indicated by the Small Particle Window and the Large Particle Window.

The first group (CAL 1-4) is ammonium chloride particles represented by the circles. These data are seen to lie along a straight line with those for the $3 \mathrm{~cm}$ path higher than those for the $1 \mathrm{~cm}$ path. The second group (CAL 5-9, CAL 6 and CAL 9 are omitted for reasons discussed previously) is ammonium chloride particles represented by squares. These data are also seen to lie along a straight line slig : tly higher than that of the first group for both path lengths. This behavior could be explained by the second group's larger particle size. The third group of data (CAL 14,15,17) is ammonium chloride particles represented by the diamonds and is a repeat of the CAL 1 data point but with humidity added to the generator in an attempt to produce smaller more compact particles. These data may have a smaller particle size than the first group and are seen to lie below the first group. The fourth group (CAL 10-12) is sodium chloride particles from an atomizer represented by the triangles. It is seen to lie along a line above the lines for all the other data.

\subsection{MODEL APPLICATION}

A theoretical model of the OLAM performance can be formulated based on the work of Brockmann (1976) and Willeke and Brockmann (1977) to evaluate the extinction coefficient for a lognormal distribution. Because the sodium chloride data was of such high quality, the data are suited for a rigorous application of the 


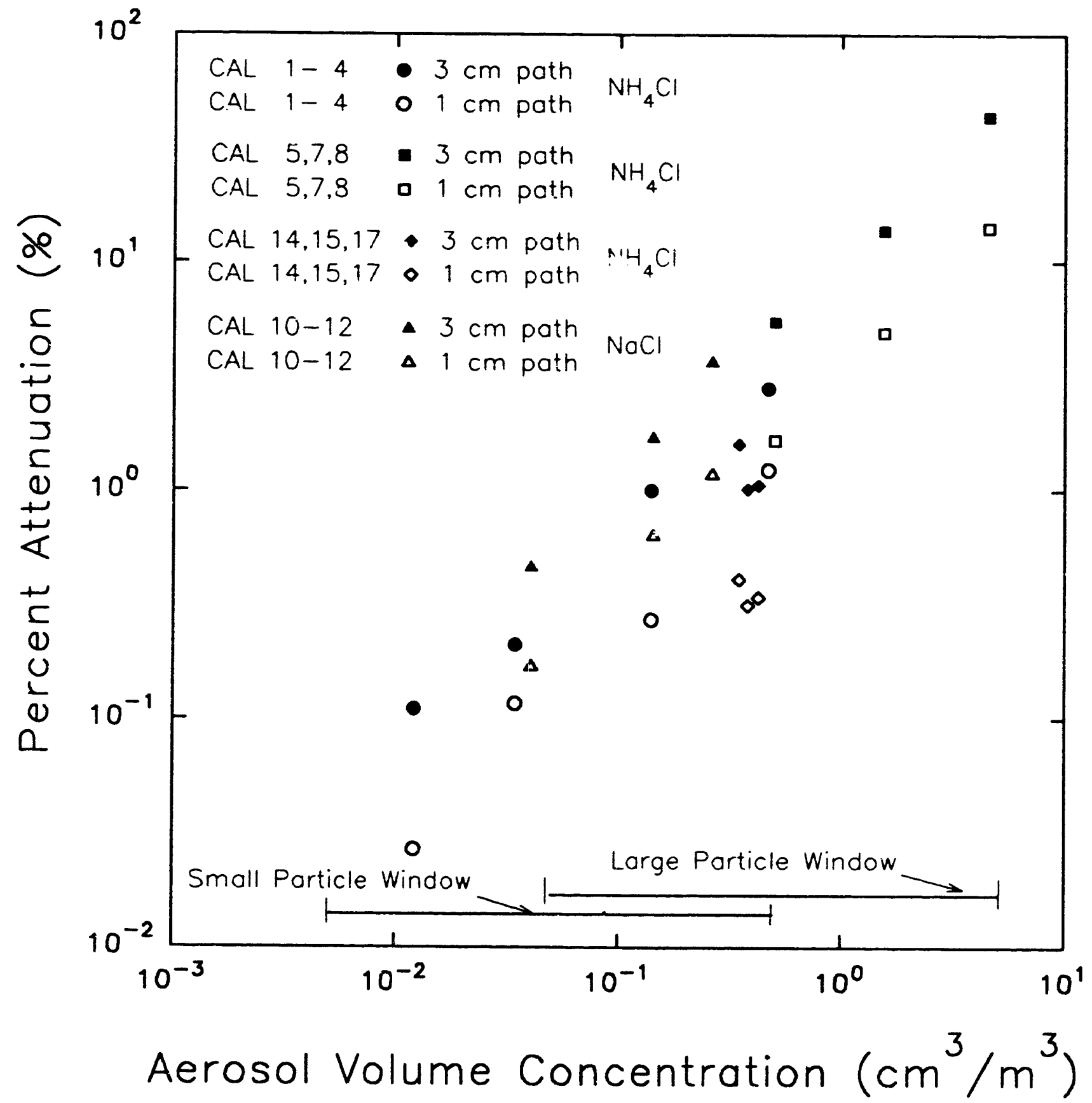

Figure 7. OLAM calibration data for $\mathrm{NH}_{4} \mathrm{Cl}$ and $\mathrm{NaCl}$ particles shown as percent attenuation as a function of aerosol volume concentration. 
model. The aerosol size distributions are based on the impactor measurement giving the geometric mass mean aerodynamic diameter, DGM $\ldots$, and the geometric standard deviation, $s_{g}$, and on the filter measurement giving the aerosol mass concentration. The density of sodium chloride is $2.165 \mathrm{~g} / \mathrm{cm}^{3}$ and is used to give the aerosol volume concentration. Assuming spherical particles, reasonable considering they are formed by spray drying, allows us to determine the geometric mass mean volume equivalent diameter, $D G M_{v o l}$ from $D_{G M}$. Using the model with the refractive index of sodium chloride of 1.544 and the log-normal distribution data from the calibration points the attenuation can be predicted. These predictions are compared to the measured attenuation data in Table 2. Excellent agreement is seen between the OLAM performance and the theors.ical model. This agreement indicates that the OLAM is operating as the theory would predict and supports the use of the theory to describe the OLAM response.

The ammonium chloride particles would appear to have a substantial void volume so that determination of the distribution parameters required for the model can not be made from the impactor measurements alone. However, model predictions for the ammonium chloride data can be made by calculating the attenuation produced by two log-normal distributions of ammonium chloride particles of refractive index 1.642, and with $\mathrm{DGM}_{\mathrm{val}}$ of 0.1 micrometers and 1.0 micrometers, and $\mathrm{s}_{\mathrm{o}}$ of 2.2. The comparisons of the data to the theoretical model are seen in Figures 8 and 9. Figure 8 plots the attenuation data as a function of the aerosol volume concentration for the $1 \mathrm{~cm}$ light path. The two theoretical response curves bound the data very well. The same result is seen in Figure 9 for the $3 \mathrm{~cm}$ light path.

These results demonstrate that the OLAM response is well described by theoretical models and that the calibration is in the range of interest.

\subsection{SUMMARY AND CONCLUSIONS}

Based on observations during the OLAM calibration, the following points appear to be pertinent:

1. These results indicate the measurable OLAM response (as indicated by percent attenuation) to aerosol volume concentration is linear on a log-log plot over the range of interest as indicated by the Large and Small Particle Windows.

2. Further, the response for a given aerosol volume concentration appears to shift by a constant ratio between the $1 \mathrm{~cm}$ and $3 \mathrm{~cm}$ paths as would be expected from application of the Lambert-Beer Law.

3. There appears to be a shift in the response curve with particle size such that larger particles at a given aerosol volume concentration will give a higher attenuation. 
Comparison of the measured values of attenuation to the values calculated from the model for calibration points 10, 11, and 12 with sodium chloride aerosol. The geometric mass mean volume equivalent diameter is calculated from the geometric mass mean aerodynamic equivalent diameter using a material density for sodium chloride of $2.165 \mathrm{~g} / \mathrm{cm}^{3}$ and assuming spherical particles at the test conditions of $8.3 \times 10^{5} \mathrm{dynes} / \mathrm{cm}^{2}$ and $21 \mathrm{C}$. The refractive index of sodium chloride used in the calculation is 1.544 . The geometric mass mean volume equivalent diameter, the geometric standard deviation, and the aerosol volume concentrations for each point are given with the measured and calculated attenuation for the $1 \mathrm{~cm}$ and $3 \mathrm{~cm}$ path lengths.

\begin{tabular}{|c|c|c|c|c|c|}
\hline $\begin{array}{c}\text { Calibration } \\
\text { Point }\end{array}$ & DGM $_{\text {val }}$ & $\mathrm{s}_{\mathrm{o}}$ & $\begin{array}{c}\text { Aerosol } \\
\text { Volume }\end{array}$ & $\begin{array}{c}\text { Measured } \\
\text { Attenuation }\end{array}$ & $\begin{array}{c}\text { Calculated } \\
\text { Attenuation }\end{array}$ \\
\hline $\begin{array}{c}\text { 1 cm Path } \\
\text { Length }\end{array}$ & & & & & $\%$ \\
\hline CAL 10: NaCl & 0.70 & 2.0 & 0.267 & 1.18 & 1.17 \\
\hline CAL 11: NaCl & 0.62 & 2.6 & 0.143 & 0.63 & 0.51 \\
\hline CAL 12: NaCl & 0.94 & 2.3 & 0.0406 & 0.17 & 0.16 \\
\hline & & & & & \\
\hline $\begin{array}{c}3 \mathrm{~cm} \mathrm{Path} \\
\text { Length }\end{array}$ & & & & & \\
\hline CAL 10: NaCl & 0.70 & 2.0 & 0.267 & 3.63 & 3.48 \\
\hline CAL 11: NaCl & 0.62 & 2.6 & 0.143 & 1.69 & 1.51 \\
\hline CAL 12: NaCl & 0.94 & 2.3 & 0.0406 & 0.46 & 0.47 \\
\hline
\end{tabular}




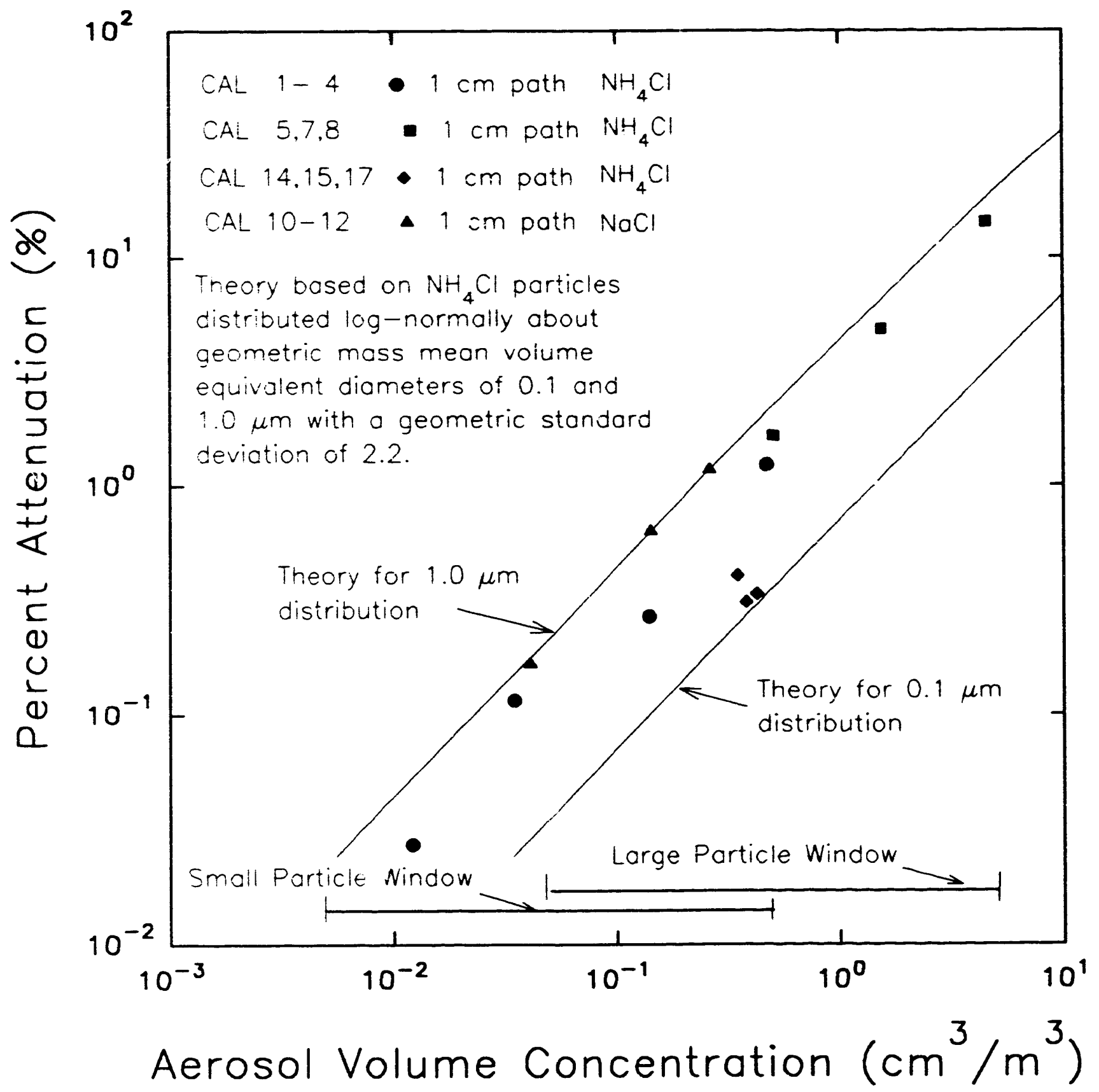

Figure 8. OLAM calibration data for $\mathrm{NH}_{4} \mathrm{Cl}$ and $\mathrm{NaCl}$ particles shown as percent attenuation as a function of aerosol volume concentration for the $1 \mathrm{~cm}$ path. The theory for particle distributions at 0.1 and 1.0 micrometer diameters is also shown and is seen to bound the data. 


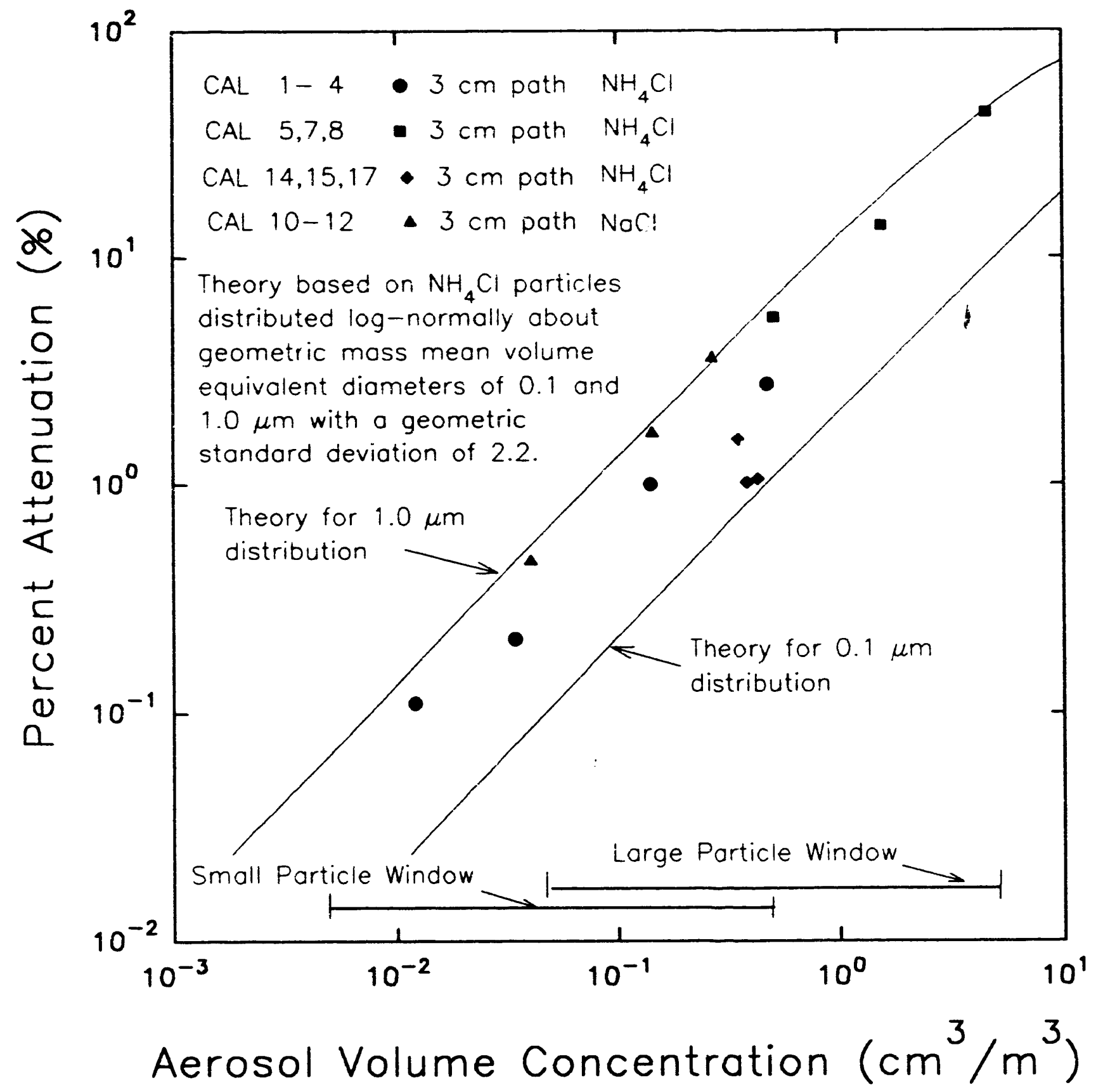

Figure 9. OLAM calibration data for $\mathrm{NH}_{4} \mathrm{Cl}$ and $\mathrm{NaCl}$ particles shown as percent attenuation as a function of aerosol volume concentration for the $3 \mathrm{~cm}$ path. The theory for particle distributions at 0.1 and 1.0 micrometer diameters is also shown and is seen to bound the data. 
4. Application of a theoretical model of OLAM response is consistent with the above observations and shews excellent agreement with the experimental data.

5. Equipment signal levels are more stable after warming up for approximately 1 hour.

6. The OLAM responds distinctly to aerosol concentrations generated during the calibration series.

7. Maintaining the purge flow to the windows is important to keep the windo: ss from fouling, especially during periods of high aerosol concentration.

8. Due to the shift in pre- and post-aerosol baseline levels, it is important to look at the amount of signal change when aerosol flows begin and end in addition to specific measurement levels.

9. System noise comprises a maximum of $1.5 \%$ of the total signal measured during calibration.

10. The minimum measurable signal is greater than $0.2 \mathrm{mV}$, or about $1.5 \%$ of the minimum signal observed during calibration.

11. Based on the system noise mentioned in 9., the practical minimum detectable attenuation may be on the level of $1 \%$ although this work was able to detect levels lower than $0.1 \%$. This work had the advantage of introducing clean gas flow at will for comparison purposes.

\subsection{REFERENCES}

Adams, J. P., Partin, J. K., Petti, D. A., Reed, T. R. (1986) "Development and calibration of an aerosol monitor used for PBF Test SFD 1-4," $4^{\text {th }}$ International Symposium on Multiphase Transport and Particulate Phenomena, Miami Beach, Florida, December, 1986.

Brockmann, J. E. (1976) "Extinction coefficients of atmospheric aerosols and use in calculating visual range and solar beam attenuation," $M$. S. Thesis, University of Minnesota, Minneapolis, MN.

Brockmann, J. E., McMurry, P. H., and Liu, B. Y. H. (1982) "Experimental Study of Simultaneous Coagulation and Diffusion Loss of Free Molecule Aerosols in Turbulent Pipe Flow," Journal of Colloid and Interface Science, 88:522-529.

Rader, D. J., Mondy, L. A., Brockmann, J. E., Lucero, D. A., and Rubow, K. L. (1991) "Stage Response Calibration of the Mark III and Marple Personal Cascade Impactors," Aerosol Science and Technology, 14:365-379 
Willeke, K and Brockmann, J. E. (1977) "Extinction coefficients for multimodal atmospheric particle size distributions," Atmospheric Environment, 11:995-999. 


\section{APPENDIX A}

\section{BEAM ATTENUATION MODEL}

The extinction coefficient, $\boldsymbol{\beta}_{\text {ext }}$, when used in the Lambert-Beer Law, defines the change in intensity of light traversing a given path length. The extinction coefficient in aerosol laden gas is generally dominated by the light scattered and absorbed by the particles and will depend on the particle size distribution, the aerosol mass concentration, particle material refractive index, and the shape of the particles. Presented here is a model for determination of the extinction coefficient based on a volumetric size distribution and concentration.

The extinction coefficient, $\boldsymbol{\beta}_{\text {oxt, }}$ is defined as

$$
\beta_{\text {ext }}=\int_{0}^{\infty} \sigma_{\text {ext }} \frac{d N}{d(\log D)} d(\log D)
$$

where

$$
\begin{array}{lll}
\sigma_{\mathrm{ext}} & \begin{array}{l}
\text { is the extinction cross section for a single particle } \\
\mathrm{dN} / \mathrm{d}(\log \mathrm{D})=
\end{array} \\
& \begin{array}{l}
\text { the aerosol number distribution function defined as the number } \\
\text { concentration of particles, } \mathrm{dN}, \text { contained in the particle size }
\end{array} \\
\mathrm{N} & \begin{array}{l}
\text { interval } \log \mathrm{D} \text { to } \log \mathrm{D}+\mathrm{dlog} \mathrm{D} . \\
\mathrm{D}
\end{array} \quad \begin{array}{l}
\text { the aerosol concentration } \\
=
\end{array}
\end{array}
$$

The extinction efficiency for a single particle, $\mathbf{Q}_{\mathbf{z x t}}$, is a function of the particle size, $D$, normalized with respect to the wavelength of the light, $\lambda$, that is , D/ $\lambda$.

Brockmann [1976] shows that

$$
\beta_{\text {oxt }}=\int_{-\infty}^{\infty} \frac{1.5 \cdot Q_{\text {ext }}}{D} \frac{d V}{d(\log D)} d(\log D)
$$

and

$$
\frac{\beta_{\text {ext }} \cdot \lambda}{V T}=\int_{-\infty}^{\infty} \frac{1.5 \cdot Q_{\text {ext }}}{D / \lambda} \frac{1}{V T} \frac{d V}{d[\log (D / \lambda)]} d[\log (D / \lambda)]
$$


where

$$
\begin{aligned}
& d V / d(\log D)=\text { the aerosol volume distribution function defined as the volume } \\
& \lambda=\text { the wavelength of light being extinguished, } \\
& \text { VT }=\text { the total aerosol volume concentration, and } \\
& \mathrm{dV} / \mathrm{d}(\log (\mathrm{D} / \mathrm{\lambda})=\text { the aerosol volume distribution function defined as the volume }
\end{aligned}
$$

The above equation is, for a given refractive index, a function of $D / \lambda$ and the aerosol volume distribution. Any distribution function may be chosen; for this application a log-normal distribution function is used. The function is defined as

$$
\frac{d V}{d(\log D)}=\frac{V T}{\sqrt{2 \pi} \log \left(\sigma_{0}\right)} \exp \left[\frac{-[\log (D / D)]^{2}}{2\left[\log \left(\sigma_{0}\right)\right]^{2}}\right]
$$

where

$\mathrm{VT}=$ the total aerosol volume concentration

$\sigma_{\mathrm{o}} \quad=$ the geometric standard deviation

$\bar{D}=$ the volume geometric mean diameter.

It can be seen from inspection that $d V / d(\log D)$ and $d V / d(\log (D / \lambda))$ are identical. Equation (A-3) can be calculated for the volume-normalized distribution at a given refractive index and wavelength to give a volume-normalized extinction coefficient, $\beta^{\prime}{ }_{\text {ext }}=\beta_{\text {ext }} / N T$, as a function of the aerosol distribution parameters $\bar{D}$ and $\sigma_{0}$. The volume- normalized extinction coefficient, $\boldsymbol{\beta}^{\prime}$ ext , multiplied by the aerosol volume concentration (the aerosol mass concentration divided by the aerosol material density) will give the extinction coefficient which when multiplied by the path length is used in the Lambert-Beer Law to calculate the light attenuation.

Expressed in this form, it is seen that the attenuation for a given aerosol size distribution is a function of the aerosol mass concentration.

Figure A-1 shows the $\beta^{\prime}$ ext surface for a refractive index of 1.6 and the OLAM wavelength of $0.84 \mu \mathrm{m}$ as a function of the distribution parameters geometric volume mean diameter, $\bar{D}$, and geometric standard deviation, $\sigma_{a}$. Figure A-2 shows values of $\boldsymbol{\beta}^{\prime}{ }_{\text {oxt }}$ as a function of mean diameter for various geometric standard deviations and as a function of geometric standard deviation for various mean diameters.

This model should allow improved analysis of data from the OLAM. The type of information that is needed is the refractive index of the aerosol material, the 
material density, mass concentration of aerosol, and the aerosol size distribution. These parameters can be determined from the experimental aerosol samples.

\section{A. 1 REFERENCES}

Brockmann, J. E. (1976) "Extinction coefficients of atmospheric aerosols and use in calculating visual range and solar beam attenuation," $M$. S. Thesis, University of Minnesota, Minneapolis, MN. 


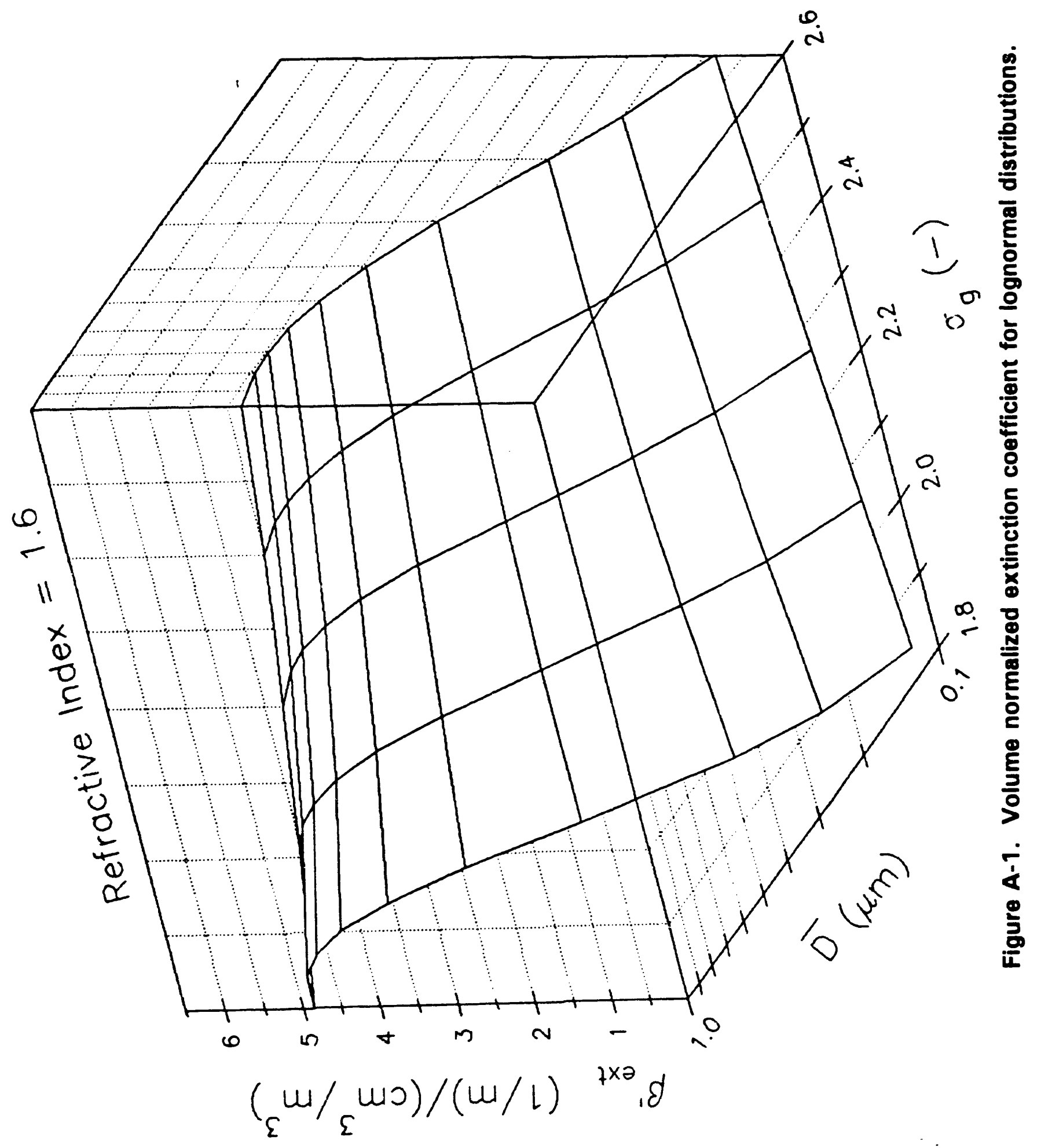



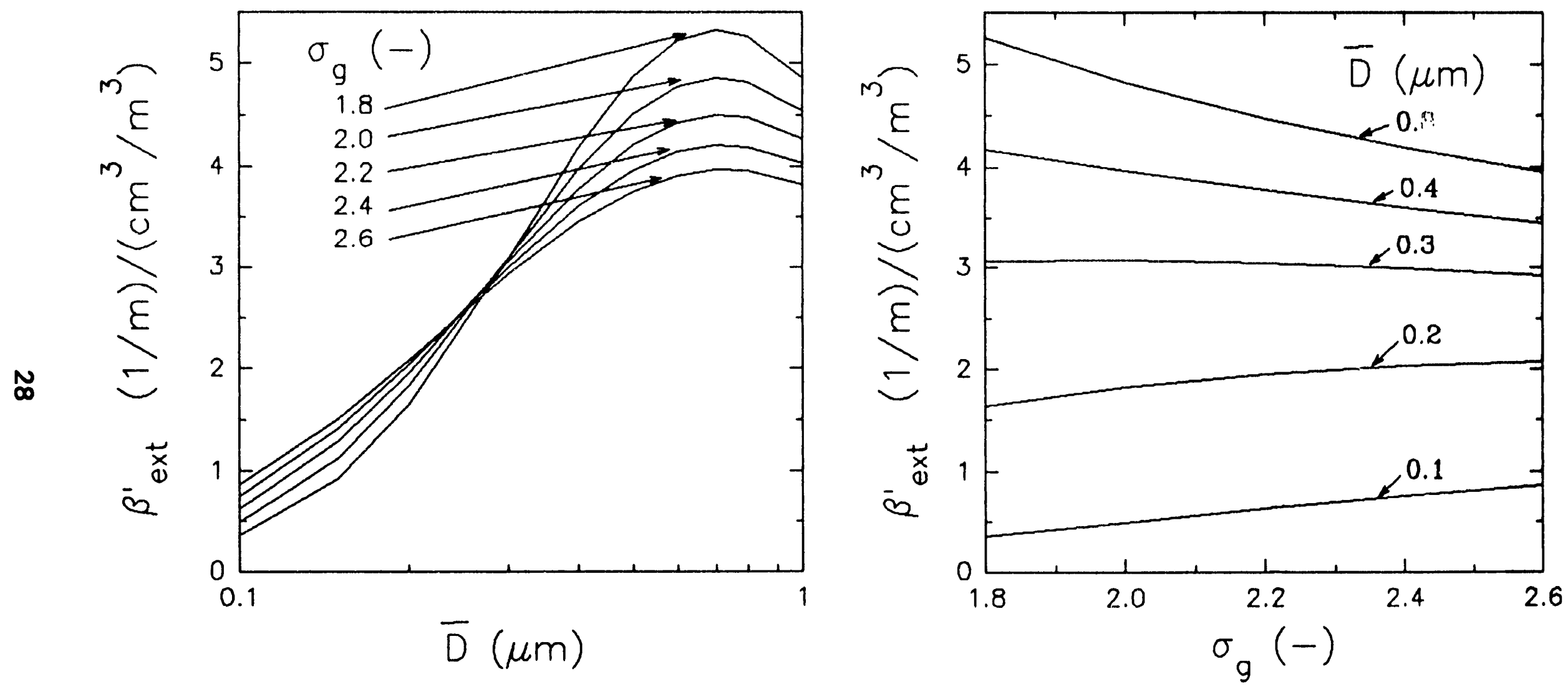

Figure A-2. Volume normalized extinction coefficient for lognormal distributions shown as a function of mean diameter for various geometric standard deviations and as a function geometric standard deviation for various mean diameters. 
U.S. Nuclear Regulatory Commission (8) Office of Nuclear Regulatory Research

Attn: E. Beckjord, NLS-007

T. Speis, NLS-007

L. Soffer, NLS-324

F. Eltawila, NLN-344

R. Y. Lee, NLN-344

A. Behbahani, NLN-344

C. Ryder, NLS-372

R. O. Meyer, NLS-013

Washington, DC 20555

U.S. Department of Energy

Attn: P. Worthington, EH-12

19901 Germantown Road

Germantown, MD 20585

University of California, Los Angeles (4)

Nuclear Energy iaboratory

Attn: I. Catton

D. Okrer: :

W. Kascenberg

G. Apostolakis

405 Hilgaard Avenue

Los Angeles, CA 90024

Idaho National Engineering Laboratory

(2)
Attn:
D. Petti
D. Hobbins

Willow Creek Building, W-3

P.O. Box 1625

Idaho Falls, ID 83415

Oak Ridge National Laboratory (2)

Attn: T. Kress

A. Wright

P.O. Box Y

Oak Ridge, TN 37830

Battelle Memorial Institute

Attn: C. A. Alexander

505 King Avenue

Columbus, $\mathrm{OH} 43201$
CEA/Cadarache/Semar (10)

Attn: M. Arnaud

M. Adroguer

M. Mailliat

M. Serre

M. Hidaka

M. Park

Mme. S. Dickinson

M. Dumaz

M. Hueber

M. Wadworth

CEA/Cadarache/SEA

(3)

Attn: M. Clement

M. Gronnier

Mme. Ktorza

CEA/Cadarache/DRS (3)

Attn: M. R. Zeyen

M. A. Meyer-Heine

M. P. VonderHardt

13108 Saint Paul Lez Durance FRANCE

CEA/FAR

Attn: Mme. C. Lecomte

60-68 Av. du G. Leclerc -B.P.6

92265 Fontenay Aux Roses Cedex FRANCE

AEA Technology (4)

Attn: A. Nichols, 102/A50

B. Bowsher, 105A/A50

D. Williams, 01/A50

J. Mitchell, 210/A32

Winfrith, Dorchester

Dorset DT2 8DH, England

UNITED KINGDOM

113 Copies for UC-523 
Japan Atomic Energy Research Institute (3)

Attn: J. Sugimoto

N. Yamano

Y. Maruyama

Tokai-mura, Naka-gun, Ibaraki-ken

319-11

JAPAN

CEC Joint Research Center, Ispra (4)

Attn: A. Jones

I. Shepherd

Y. Drossinos

ISPRA

J. Capitao

21020 Varese

ITALY

Professor Augustin Alonso

Polytechnical University of Madrid

ETS Ingenieros Industriiales

Jose Gutierrez Abascal 2

28006 Madrid

SPAIN

K.D. Hocke

Universitat Stuttgart IKE

Postfach 1801140

D-7000 Stuttgart 80

GERMANY

K. Trambauer

Gesellschaft fur Reaktorischerheit (GRS)

$\mathrm{mbH}$

Forschungsgelande

D-8046 Garching

GERMANY

Akira Nonaka, Manager

Equipment and Components Department

NUPEC

Nuclear Power Engineering Center

Shuwa-kamigacho Bldg.

3-13, 4-Chome, Toranomon Minato-ku

Tokyo 105

JAPAN
Kim, Han Chul, Senior Researcher

Severe Accident Assessment Department

P.O. Box 16

Kaeduk-Danji

Taejon, KOREA 305-606

Kenji Takumi

Director and General Manager

Equipment and Components Department Nuclear Power Engineering Center

Shuwa-kamyacho Bldg.

3-13, 4-Chome, Toranomon Minato-ku

Tokyo 105, JAPAN

Dr. Siegfried Hagen

Kemforschungszentrum Karlsruhe Gmbh Postfach 3640

D-7500 Karlsruhe 1

GERMANY

SANDIA DISTRIBUTION:

MS0100 Document Processing for DOE/OSTI (10)

MS0619 Technical Publications

MS0728 J.L. Sprung

MS0736 N.R. Ortiz

MS0739 K.K. Murata

MS0739 K.E. Washington

MS0739 D.C. Williams

MS0742 J. Kelly

MS0744 D.A. Powers

MS0744 W.A. von Riesemann

MS0745 S.L. Thompson

MS0747 A.L. Camp

MS0748 T.D. Brown

MS0748 F.T. Harper

MS0748 J.C. Helton

MS0748 L.A. Miller

MS0834 J.E. Brockmann (15)

MS0899 Technical Library (5)

MS1137 M.D. Allen

MS1137 N. Bixler

MS1137 T.K. Blanchat

MS1137 T.Y. Chu

MS1137 R.M. Elrick

MS1137 T.J. Heames

MS1144 J.V. Walker

MS9018 Central Technical Files 


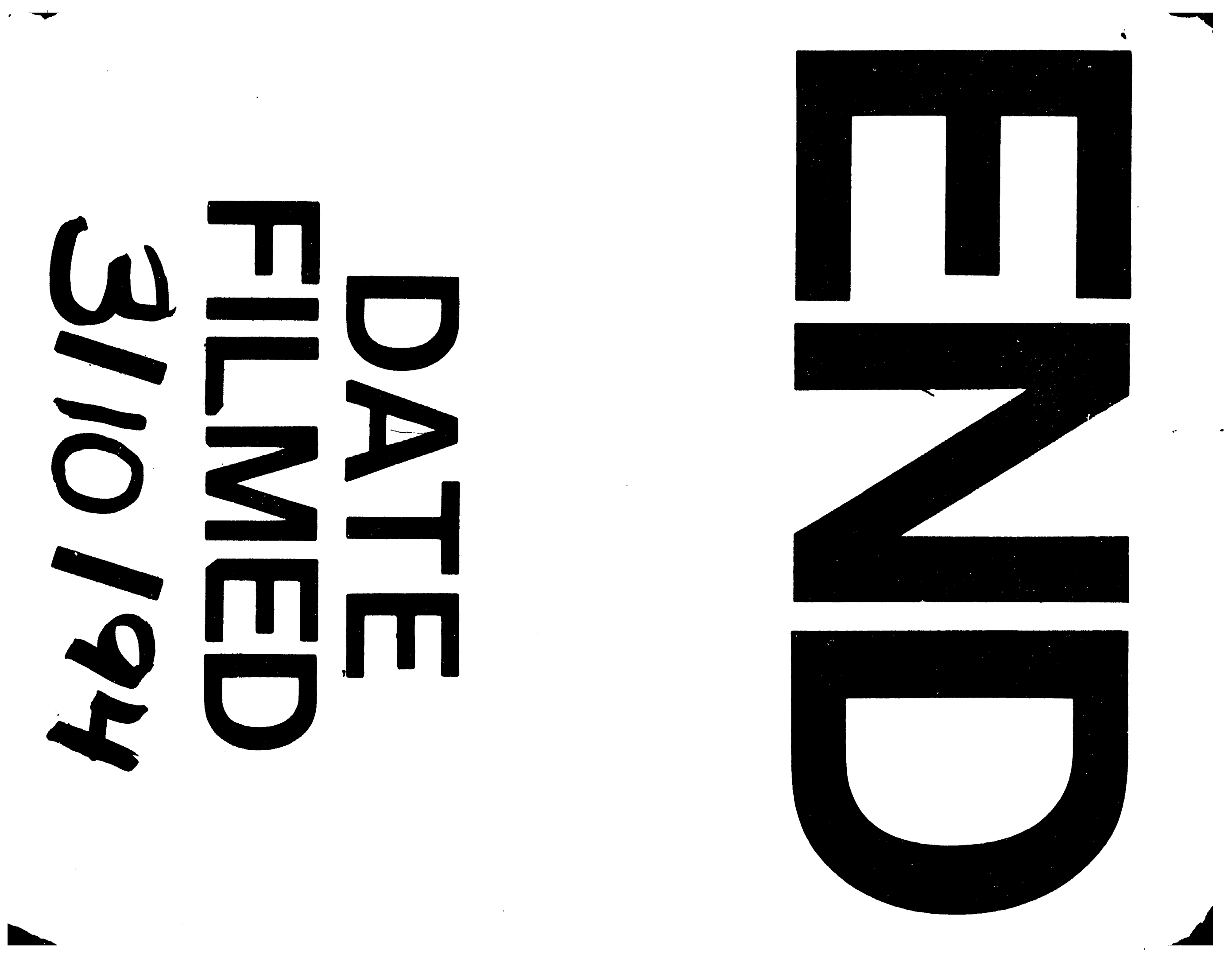

